\title{
Pendampingan Eskalasi Bisnis UKM Mina Indo Sejahtera Melalui Diversifikasi dan Nilai Tambah Produk Olahan Lele Sehat
}

\author{
Business Escalation Assistance of Mina Indo Sejahtera SME Through Diversification \\ and Added Value of Healthy Catfish Processed Products
}

\author{
Pramudi Arsiwi ${ }^{1}$, Prajanto Wahyu $\mathrm{Adi}^{2}$, Dony Satriyo Nugroho ${ }^{3}$, Probo Kusumo ${ }^{4}$ \\ 1,3,4 Program Studi Teknik Industri, Fakultas Teknik \\ ${ }^{2}$ Program Studi Teknik Informatika, Fakultas Ilmu Komputer \\ 1,2,3,4 Universitas Dian Nuswantoro, Semarang \\ E-mail: 1'pramudi.arsiwi@dsn.dinus.ac.id, ${ }^{2}$ prajanto@dsn.dinus.ac.id, \\ dony.satriyo.n@dsn.dinus.ac.id, ${ }^{4}$ probokusuma86@gmail.com
}

\begin{abstract}
Abstrak
Kesehatan pribadi menjadi isu nomor satu dalam prioritas hidup 73\% masyarakat Indonesia. Hal ini tentunya merupakan sebuah peluang bagi UKM Mina Indo Sejahtera untuk melakukan eskalasi bisnis terkait dengan produk olahan pangan berbahan dasar lele organik sehat non antibiotik, dan mengambil ceruk pasar tersebut sebagai segmen pasar untuk produknya. Karena segmen pasar yang dituju merupakan segmen khusus, maka diperlukan pula sebuah produk yang berkualitas baik serta strategi pemasaran yang sesuai dengan karakter ceruk pasar tersebut. Pelaksanaan pengabdian ini dilakukan dengan melakukan pendampingan terhadap UKM Mina Indo Sejahtera, untuk menjalankan eskalasi bisnis melalui diversifikasi produk yang berupa Nugget Lele sehat non - antibiotik. Kegiatan dimulai dengan perencanaan bahan dan alat yang digunakan untuk menunjang produk olahan Nugget Lele sehat non - antibiotik, yang terdiri dari alat pendukung kegiatan produksi dan desain packaging serta labeling. Kemudian dilakukan uji coba produksi Nugget Lele dengan alat dan bahan tersebut, termasuk juga dilakukan tes lab untuk menguji kandungan cemaran kimia pada bahan baku lele, demi memenuni uji standar pangan. Selain itu, diberikan juga pendampingan terkait dengan strategi pemasaran yang efektif, dengan penggunaan Search Engine Optimisation sebagai pendukung, yang juga dapat menjadi nilai tambah produk dan dapat mendukung kesuksesan rencana eskalasi bisnis UKM tersebut.
\end{abstract}

Kata kunci: UKM, eskalasi bisnis, nilai tambah, ikan lele

\begin{abstract}
Personal health is the number one issue in the life priorities of $73 \%$ of Indonesians. This is certainly an opportunity for UKM Mina Indo Sejahtera to escalate business related to processed food products based on healthy organic non-antibiotic catfish, and to take this market niche as a market segment for its products. Because the target market segment is a special segment, it is also necessary to have a good quality product and marketing strategy that is appropriate to the character of the niche market. The service is carried out by assisting Mina Indo Sejahtera UKM, to carry out business escalation through product diversification in the form of healthy nonantibiotic catfish nuggets. The activity began with the planning of materials and tools used to support non-antibiotic healthy catfish Nugget processed products, which consisted of supporting tools for production activities and packaging design and labeling. Then testing the production of catfish nuggets with these tools and materials, including a lab test to test the chemical contamination content of catfish raw materials, in order to fulfill the food standard test. In addition, assistance is also provided in relation to an effective marketing strategy, with the use of
\end{abstract}


Search Engine Optimization as a support, which can also be a value added product and can support the success of the SME business escalation plan.

Keywords: SME, business escalation, added value, catfish

\section{PENDAHULUAN}

Jawa Tengah merupakan sebuah Provinsi yang memiliki 4,8 juta unit UMKM, dimana 137.000 diantaranya telah dibina oleh Dinas Koperasi, Usaha Kecil Menengah Jawa Tengah. Jumlah UMKM di Jawa Tengah yang selalu meningkat secara signifikan, harus diikuti dengan adanya perkembangan kualitas, agar UMKM mampu bersaing dengan kompetitor di Pasar Usaha (Semarang Bisnis, 2019). Salah satu bidang UMKM yang ada di Jawa Tengah adalah bidang usaha pengolahan dan pemasaran ikan, dengan jumlah mencapai 955 unit pada tahun 2016, yang terdiri dari usaha perseorangan maupun kelompok (OJK, 2016).

Kota Semarang merupakan salah satu kota yang ada di Provinsi Jawa Tengah. Salah satu UKM di Kota Semarang yang bergerak di bidang pengolahan ikan adalah UKM Mina Indo Sejahtera, yang beralamat di Jalan Pamularsih I no. 18, Bojongsalaman, Kecamatan Semarang Barat, Kota Semarang. UKM Mina Indo Sejahtera yang berjarak sekitar 3,7 kilo meter dari Kampus Udinus ini, juga merupakan UKM binaan Dinas Kelautan dan Perikanan Kota Semarang. UKM inilah yang menjadi mitra dalam kegiatan Pengabdian Masyarakat ini.

UKM Mina Indo Sejahtera bergerak di bidang budidaya dan pengolahan ikan lele. Ikan lele yang dibudidayakan di UKM ini memiliki kualitas yang sangat tinggi sesuai dengan standar komoditas ekspor, yaitu sehat (non - antibiotik) dan higienis (anti bakteri e. coli). Hal ini dikarenakan, segmen pasar yang dituju oleh UKM Mina Indo Sejahtera termasuk dalam ceruk pasar, yaitu segmen menengah keatas yang mengedepankan konsumsi pangan berbahan organik demi menjaga pola hidup sehat. Hal ini tentu merupakan sebuah potensi, mengingat adanya hasil survey yang dilakukan oleh PT. Sun Life Financial Indonesia, bahwa 73\% masyarakat menempatkan kesehatan pribadi menjadi isu nomor satu dalam prioritas hidup (Bisnis.com, 2015).

Selain hasil budidaya sendiri, UKM Mina Indo Sejahtera juga bekerjasama dengan sepuluh peternak lele sehat yang masih berskala kecil, yang berperan sebagai penyuplai bahan baku tambahan berupa ikan lele sehat non - antibiotik. Produk yang dijual oleh UKM Mina Indo Sejahtera tidak hanya berupa lele segar, namun juga berupa produk olahan ikan lele bernama "LeBoem", yaitu ikan lele yang sudah dibumbui serta dikemas dalam kemasan vakum dan siap digoreng. Karena segmen pasar yang dituju merupakan segmen khusus, maka diperlukan pula sebuah produk yang memiliki kualitas yang baik, yang hal tersebut dapat dicapai apabila penerapan standar mutu yang tinggi sudah diterapkan dari sejak proses produksi, memiliki sarana prasarana produksi dan packaging yang baik, serta metode promosi yang sesuai dengan karakter segmen pasar yang dituju.

Selama ini, ikan lele sehat non - antibiotik hasil panen di UKM Mina Indo Sejahtera dan suplai dari sepuluh mitra peternak - peternak kecil lainnya, hanya dijual dalam bentuk lele segar (fresh) dan "Leboem", yaitu varian olahan lele vakum siap goreng yang sudah dibumbui. Dengan adanya diversifikasi produk olahan ikan lele yang berupa Nugget Lele ini, diharapkan mampu memberikan nilai tambah tersendiri untuk produk olahan berbahan dasar ikan lele. Selain itu juga diharapkan dapat memberikan dampak yang positif bagi UKM Mina Indo Sejahtera dan para mitra peternak lele sehat, yaitu berupa peningkatan nilai ekonomi dari usaha ikan lele yang mereka kelola. Nilai ekonomi yang dimaksud adalah, pada saat UKM Mina Indo Sejahtera dapat menjual produk dengan value lebih, maka nantinya mereka juga dapat membeli lele sehat non - antibiotik segar dari para mitra peternak dengan harga beli yang lebih tinggi pula. 
Dengan adanya program Pengabdian Masyarakat ini, diharapkan nantinya dapat memberikan pemahaman dan pendampingan bagi UKM Mina Indo Sejahtera, khususnya dalam hal eskalasi bisnis melalui diversifikasi produk olahan ikan lele sehat yang memiliki nilai tambah dan nilai ekonomi, sehingga dapat meningkatkan kesehjahteraan UKM Mina Indo Sejahtera serta pihak - pihak yang terkait.

\section{METODE PELAKSANAAN}

Pengabdian ini dilakukan mulai bulan Desember 2019 sampai dengan bulan Maret 2020. Mitra yang terlibat dalam kegiatan Pengabdian Masyarakat ini adalah UKM Mina Indo Sejahtera yang beralamat di Jalan Pamularsih I no. 18, Bojongsalaman, Kecamatan Semarang Barat, Kota Semarang.

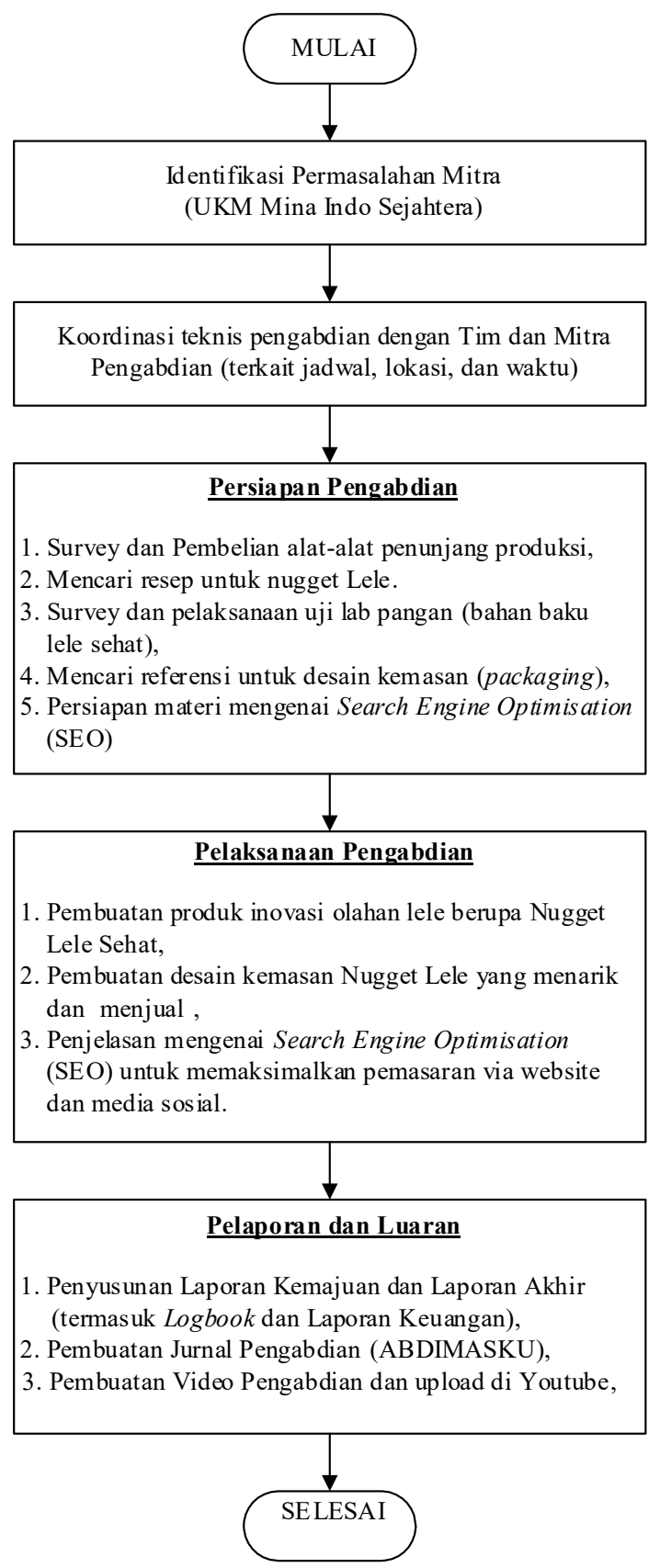

Gambar 1 Tahap Pelaksanaan Pengabdian UKM Mina Indo Sejahtera 2019/2020 
Pengabdian ini berisi beberapa tahapan kegiatan, yaitu tahap persiapan, tahap pelaksanaan, dan tahap pelaporan. Pada tahap persiapan, kegiatan yang dilakukan adalah melakukan survey dan pembelian alat-alat penunjang produksi, mencari komposisi resep untuk pembuatan nugget lele, surveydan pelaksanaan uji lab bahan baku lele (uji cemaran kimia), mencari referensi-referensi untuk desain kemasan nugget lele, dan persiapan materi mengenai Search Engine Optimisation (SEO).

Untuk tahap pelaksanaan juga mencakup beberapa kegiatan, yaitu pembuatan produk inovasi berbahan dasar lele sehat yaitu berupa Nugget Lele yang kemudian disebut "Nuggle". Untuk menunjang produk tersebut, dibuat juga desain kemasan untuk "Nuggle" dengan desain yang kreatif dan inovatif. Sebagai pendukung akhir, dilakukan juga pendampingan mengenai pemanfaatan SEO untuk memaksimalkan pemasaan, khususnya melalui social media dan website. Setelah rangkaian kegiatan pengabdian selesai, tahap akhir adalah pelaporan. Secara detailnya, tahap pelaksanaan kegiatan Pengabdian Masyarakat ini dapat dilihat pada Gambar 1.

\section{HASIL DAN PEMBAHASAN}

Kegiatan pengabdian dengan judul "Pendampingan Eskalasi Bisnis UKM Mina Indo Sejahtera Melalui Diversifikasi dan Pemberian Nilai Tambah Produk Olahan Lele Sehat NonAntibiotik" telah selesai dilaksanakan dalam waktu sekitar empat bulan. Kegiatan tersebut diawali dengan tahap persiapan yang merupakan awal dimulainya pengabdian. Koordinasi awal dilakukan dengan melibatkan mitra, yaitu pemilik dan karyawan UKM Mina Indo Sejahtera seperti terlihat pada Gambar 2. Koordinasi tersebut membahas mengenai rencana penambahan nilai pada produk olahan lele sehat, rencana survey uji lab, persiapan desain kemasan, dan rencana pemasaran yang didukung dengan Search Engine Optimisation (SEO).

Pada tahap pelaksanaan, dimulai dengan proses pembuatan nugget lele. Sebelum membuat nugget lele, diperlukan uji coba untuk melakukan presto daging lele, agar mempermudah dalam penggilingannya, seperti terlihat pada Gambar 3. Selanjutnya dilakukan diskusi lanjutan mengenai desain kemasan Nuggle.

Kegiatan pengabdian diakhiri dengan pendampingan dan sosialisasi hasil percobaan kepada mitra UKM Mina Indo Sejahtera. Dalam kegiatan pendampingan tersebut, mitra tampak antusias sekali untuk berdiskusi dengan tim pengabdi. Banyak sekali hal yang didiskusikan terkait dengan produk nugget lele, desain kemasan, dan SEO untuk memaksimalkan pemasaran. Kegiatan pendampingan ini dapat dilihat pada Gambar 4.

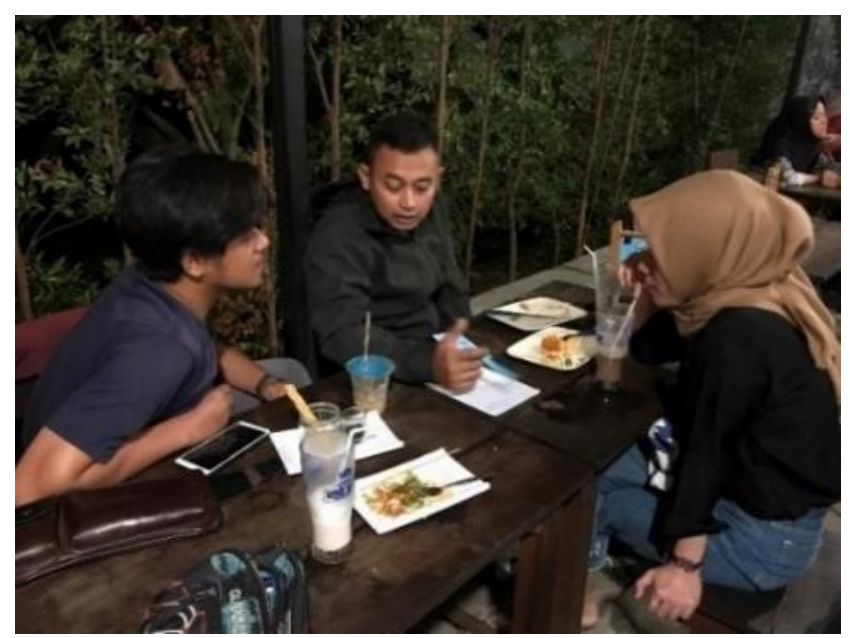

Gambar 2 Koordinasi Awal Pengabdian 
Secara singkat, rangkaian kegiatan Pengabdian yang telah selesai dilaksanakan, menghasilkan beberapa hasil. Yang pertama adalah nugget lele yang kemudian dinamakan dengan "Nuggle", seperti terlihat pada Gambar 5. Kemudian ada desain kemasan untuk produk "Nuggle" seperti terlihat pada Gambar 6. Bahan baku lele sehat non-antibiotik yang digunakan untuk pembuatan Nuggle, juga sudah dilakukan uji lab cemaran kimia dan mendapatkan hasil negative. Artinya lele yang digunakan sebagai bahan baku pembuatan Nuggle, bebas dari bahan berbahaya dan aman untuk dikonsumsi.
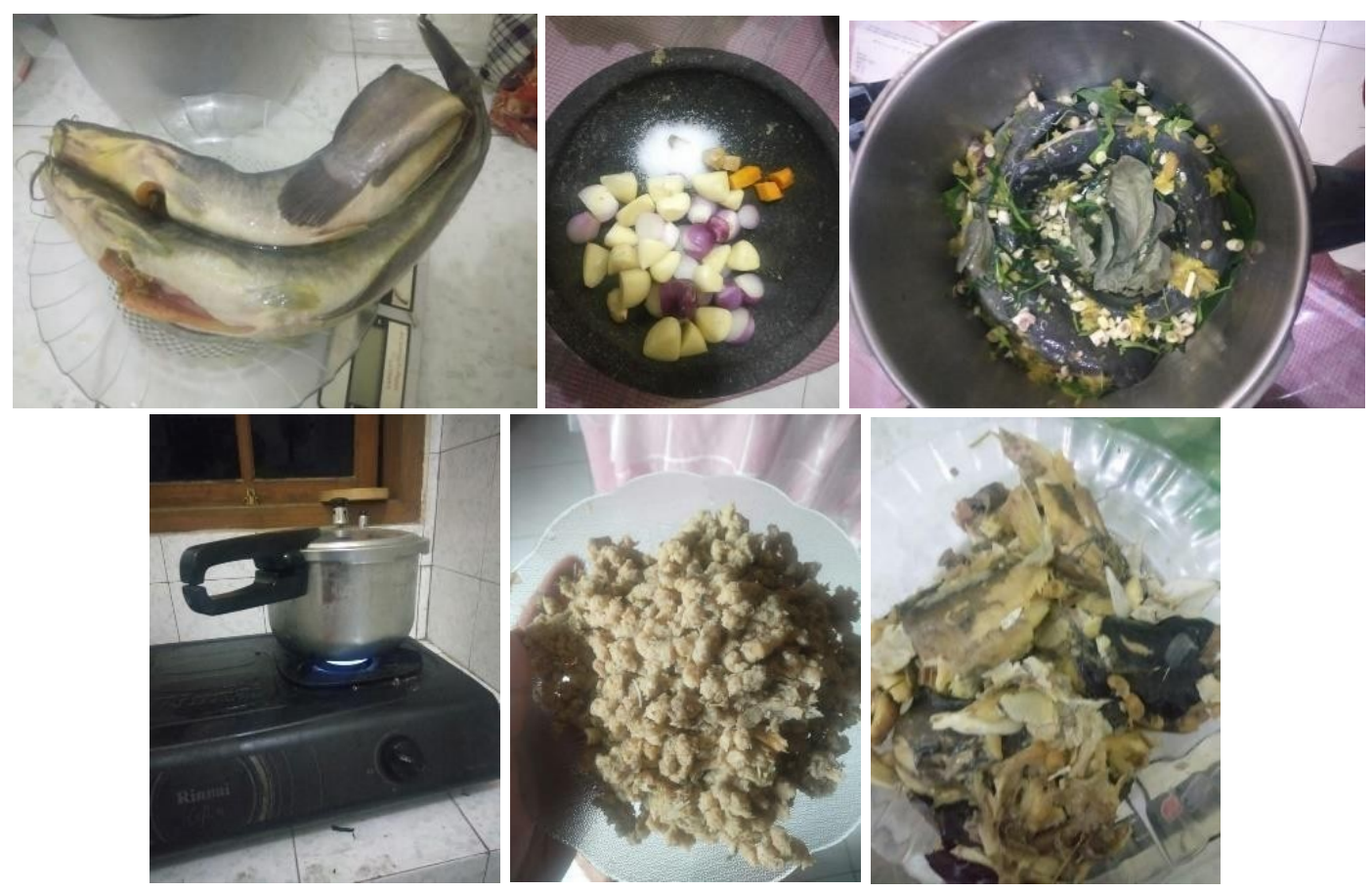

Gambar 3 Uji Coba Presto Daging Lele Sehat Non-Antibiotik
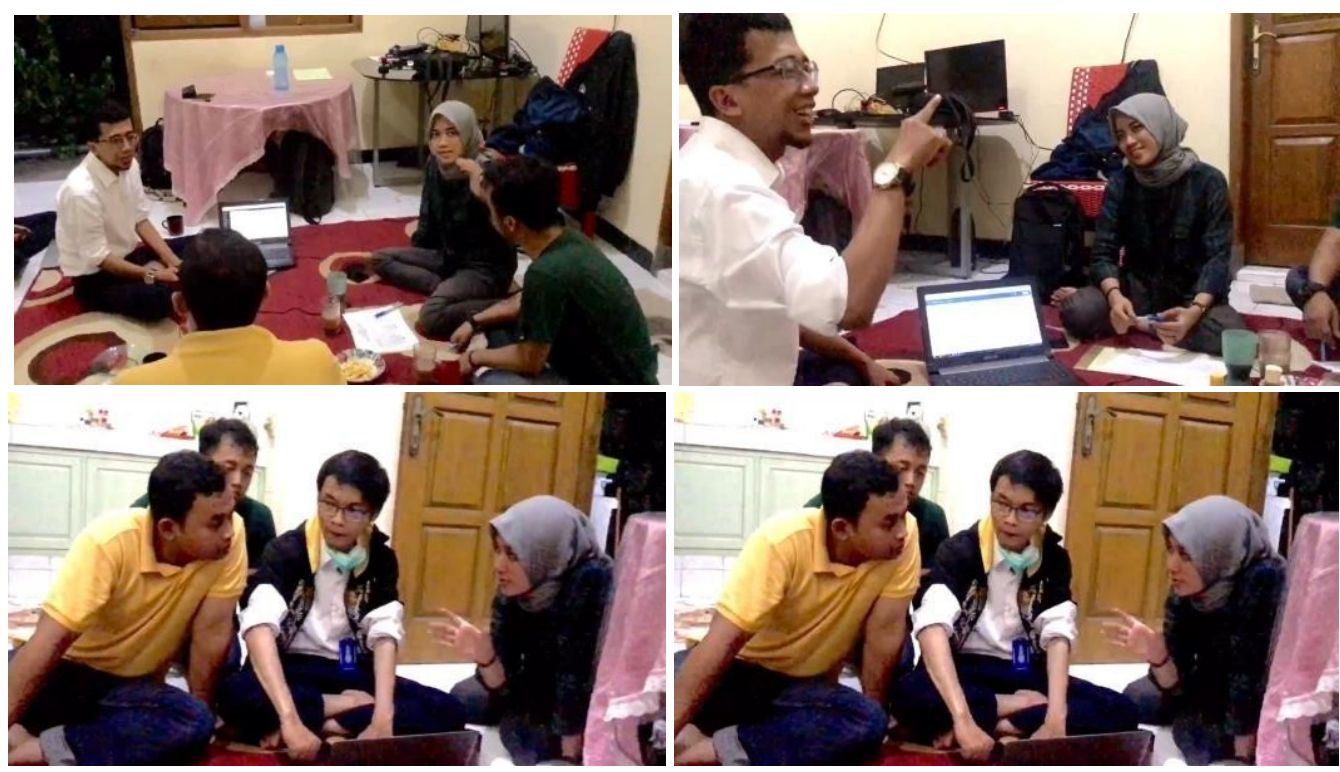

Gambar 4 Pendampingan Pada Mitra Terkait Produk Nugget Lele, 

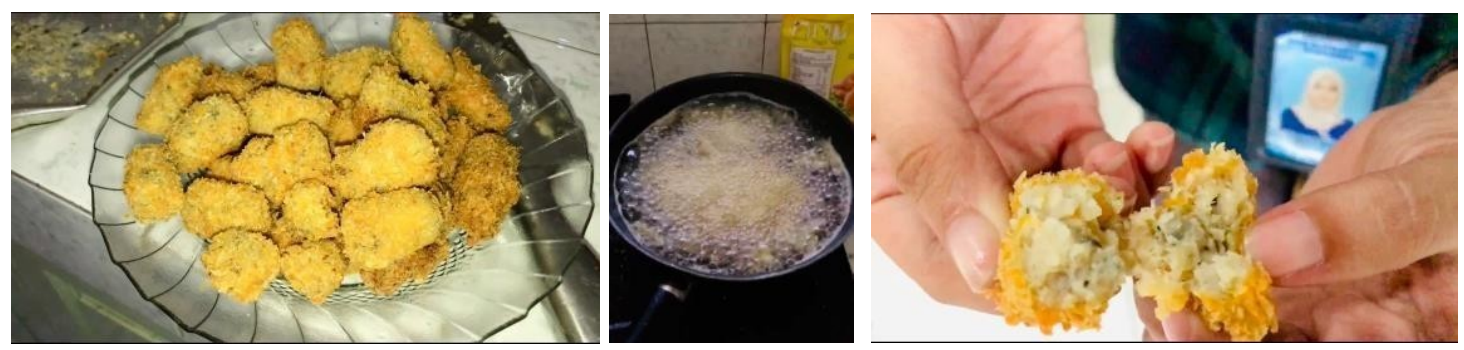

Gambar 5 Produk Nugget Lele Sehat "Nuggle"

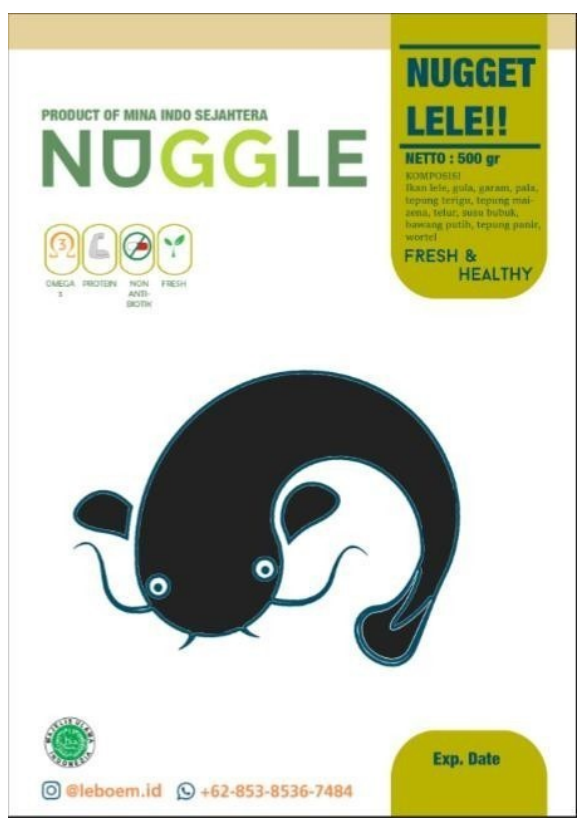

Gambar 6 Produk Nugget Lele Sehat "Nuggle"

\section{KESIMPULAN DAN SARAN}

Program Pengabdian telah selesai dijalankan dengan baik serta lancar, sesuai dengan rencana kegiatan yang telah disusun. Mitra pendampingan sangat mengapresiasi dan senang dengan adanya kegiatan pengabdian ini, dikarenakan sangat membantu UKM Mina Indo Sejahtera dalam menciptakan inovasi produk baru berbahan dasar lele sehat, untuk memberikan nilai tambah pada produk Lele sekaligus menciptakan keunggulan kompetitif agar UKM lebih siap bersaing dengan pesaing lain, khususnya yang bergerak di bisnis olahan pangan organik. Produk inovasi olahan lele tersebut berupa Nugget Lele sehat, yang dikemas dalam netto 500 gram. Desain kemasan yang dibuat juga sangat menarik, sehingga dapat menambah nilai produk serta menjaga keamanan pangan dari produk Nugget Lele. Dari sisi pemasaran pun juga telah dijelaskan mengenai pemanfaatan Search Engine Optimisation (SEO) untuk memaksimalkan pemasaran via website dan media sosial.

Berdasarkan evaluasi yang telah dilakukan, terdapat beberapa saran untuk kegiatan pengabdian kedepannya, yaitu Pengabdian ke depannya hendaknya juga berfokus pada penambahan value dari aspek-aspek lainnya, misalkan alternatif bahan baku utama lain, sehingga 
tidak monoton pada produk olahan berbahan dasar lele saja. Kemudian jika memungkinkan, sebaiknya netto produk dalam kemasan dibuat dalam beberapa ukuran, sehingga akan membuat konsumen lebih mudah dalam menentukan pilihan saat membeli produk dari UKM Mina Indo Sejahtera. Search Engine Optimisation (SEO) ada baiknya juga tidak hanya dijelaskan, namun juga diterapkan meskipun secara sederhana, kemudian dinilai efektivitasnya dalam meningkatkan pemasaran UKM Mina Indo Sejahtera nantinya.

\section{UCAPAN TERIMA KASIH}

Penulis mengucapkan terima kasih kepada Lembaga Penelitian dan Pengabdian Kepada Masyarakat (LP2M) Universitas Dian Nuswantoro atas pendanaan pada Pengabdian ini melalui Skema Hibah Pengabdian Kepada Masyarakat (137/A.38.04/UDN-09/XI/2019). Ucapan terimakasih juga diberikan kepada UKM Mina Indo Sejahtera yang telah bersedia menjadi mitra dalam kegiatan Pengabdian Masyarakat ini.

\section{DAFTAR PUSTAKA}

[1] https://kumparan.com/karjaid/benarkah-99-9-persen-jumlah-unit-usaha-di-indonesiaadalah-umkm-1552834338532079419, diakses pada tanggal 11 Oktober 2019 (a)

[2] https://lifestyle.bisnis.com/read/20151113/220/491709/hasil-survei-kesadaran-hidup-sehatmasyarakat-meningkat, diakses pada tanggal 12 Oktober 2019

[3] https://semarang.bisnis.com/read/20190312/536/898741/dinkop-pacu-ukm-jateng-naikkelas, diakses pada tanggal 11 Oktober 2019 (b)

[4] https://www.ojk.go.id/sijaring/id/sektor-kelautan-dan-perikanan/usaha-pengolahan-produkkelautan-dan-perikanan/detail-dokumen.aspx?dokumenid=16, diakses pada tanggal 11 Oktober 2019 (c) 